\title{
Stage 2A Neuroblastoma
}

National Cancer Institute

\section{Source}

National Cancer Institute. Stage 2A Neuroblastoma. NCI Thesaurus. Code C102845.

Localized tumor with incomplete gross excision; representative ipsilateral nonadherent lymph nodes negative for tumor microscopically. (cancer.gov) 